\title{
ALGUNAS CRÍTICAS AL DERECHO COMÚN Y ESPECIALMENTE A LA REGULACIÓN DE LAS INCAPACIDADES RESPECTO DEL ADULTO MAYOR EN EL ORDENAMIENTOJURÍDICO CHILENO
} SOME CRITICISMS TO THE COMMON LAW
AND ESPECIALLY TO THE INCAPACITIES
OF THE OLDER ADULT IN THE CHILEAN LAW Rodrigo Barcia Lehmann*

A la memoria del gran profesor Gonzalo Figueroa ${ }^{1}$.

\section{RESUMEN}

Este trabajo analiza la ancianidad desde la perspectiva del Derecho Civil y concretamente desde la capacidad. En Chile se ha avanzado en la protección de la ancianidad desde las políticas públicas, pero no ha habido la misma preocupación respecto de los adultos mayores como sujetos de Derecho. La mirada de nuestra legislación hacia los ancianos, desde la capacidad, es sumamente limitada y poco respetuosa de sus derechos

\footnotetext{
* Licenciado en Ciencias Jurídicas y Sociales, Universidad Central de Chile, 1991; MBA Economía y Dirección Internacional de Empresas, MEDI, Universidad Autónoma de Madrid, 1997; European Master in Law and Economics, Complutense und Hamburg Universität, 1998 y doctor en Derecho Civil, Universidad Complutense de Madrid, 2002. Profesor de Derecho Civil jornada completa, Facultad de Derecho, Universidad Finis Terrae. Dirección postal: avenida Pedro de Valdivia No 1509 , Providencia, Chile. Artículo recibido el 21 de julio de 2014 y aceptado para su publicación el 1 de octubre de 2014. Correo electrónico: rbarcia@uft.cl.

${ }^{1}$ Para destacar la avanzada percepción que tenía Gonzalo Figueroa en torno a los fenómenos jurídicos, sus estudios se centraron, en los últimos años, en las nuevas tecnologías, especialmente aplicadas al Derecho de la Personalidad. Así, nos señalaba: "en mi calidad de profesor de Derecho Civil comprendí que los nuevos descubrimientos estaban llamados a producir una transformación revolucionaria en esa especialidad jurídica [se refiere a la Biotecnología], sobre todo en materia de plazos para fijar la concepción a partir del nacimiento, de determinación de la paternidad y la maternidad, de filiación y de sucesión por causa de muerte, y que -además- esos descubrimientos podrían abrir anchas puertas a la discriminación por causas genéticas, permitiendo que el antiguo racismo deviniera en genetismo". FigueroA (2011), p. 11.
} 
individuales. A esta conclusión se llega después de analizar las reglas que regulan la demencia -como criterio de protección del adulto mayor y fomento de su capacidad disminuida-, y la forma en que se podría tratar de lograr una mayor autonomía en la ancianidad, a través de la regulación del Código Civil, que se muestra como impotente a este respecto.

Palabras clave: personas mayores, derechos extraeconómicos, incapacidad o discapacidad, ancianidad.

\section{Abstract}

This work analyzes the old age, from the perspective of civil law and specifically from the capacity. In Chile there has been progress in the protection of the elderly from a public policy, but has not been the same concern with regard to older adults as subjects of law. The gaze of our legislation toward the elderly, from the capacity, is extremely limited and pays little respect for their individual rights. This conclusion can be reached after analyzing the rules governing the dementia -as a criterion for protection of the elderly and promotion of his diminished capacity-, and how it could be trying to achieve a greater autonomy in old age, through the regulation of the Civil Code, which shows how impotent in this regard.

Keywords: Elderly, non-pecuniary rights, inability and incapacity, older adult.

\section{INTRODUCCIÓN}

El Derecho chileno ha sido objeto de muchas modificaciones los últimos años tendientes a actualizarlo, sobre todo respecto de los Derechos de la Personalidad. Así, se ha igualado la calidad de los hijos, separando los efectos del matrimonio de la filiación -a través de la $\mathrm{LF}^{2}$-, se ha aceptado el divorcio e incorporado la compensación económica, como una forma de permitir los denominados acuerdos implícitos de distribución de funciones en el matrimonio ${ }^{3}$, y se han llevado a cabo importantes reformas sustantivas y procesales al Derecho de Familia y la Infancia a través de la LTF. Estas reformas han llevado a que el matrimonio pueda terminar mediante un convenio regulador, denominado legalmente como acuerdo

\footnotetext{
${ }^{2}$ Barcia (2000), pp. 13-29.

${ }^{3}$ Barcia y Riveros (2011), pp. 249-278.
} 
completo y suficiente ${ }^{4}$, que se haya incorporado el concepto de cónyuge débil y que los principios de igualdad de los cónyuges y de los padres y del interés superior del niño sean considerados como principios basales del Derecho ${ }^{5}$. Sin embargo, también ha habido retrocesos, como la fallida incorporación del cuidado personal compartido en la ley $\mathrm{N}^{\circ} 20.680$ de $2013^{6}$, que afecta fuertemente los derechos y facultades del padre no custodio.

Las reformas precedentes no han sido introducidas a nuestro Derecho de forma programática, sino que han sido el colorario de una suma de modificaciones que han generado grandes disputas ideológicas, más que técnicas o doctrinales ${ }^{7}$. Entre estas discusiones hay una que ha sido relegada a un segundo plano y tiene una relevancia fundamental, como lo es la capacidad o, si se quiere, la incapacidad. Un derecho civil centrado en un concepto de capacidad, que se basa en el patrimonio no sirve para explicar en la actualidad esta figura. El Derecho clásico ignora una fase fundamental de la capacidad, como lo es la aptitud para celebrar actos extrapatrimoniales, que ya no se basa en un derecho de carencias, como lo hace el Derecho moderno, que fundamenta la capacidad en el patrimonio, sino que se sustenta en los derechos fundamentales como sucede en la posmodernidad. Naturalmente, el Código de Andrés Bello, dada su data, no se pudo hacer cargo de estos importantes cambios sociales. Esta concepción de la capacidad, anquilosada en el pasado, afecta la infancia y la adolescencia, pero también la ancianidad y los trastornos mentales. El Derecho Comparado ha avanzado lenta, pero inexorablemente desde mediados del siglo xx, en la regulación de la capacidad, lo que lamentablemente no ha ocurrido entre nosotros, que nos hemos quedado rezagados respecto de esta evolución.

En resumidas cuentas, las reglas que regulan la capacidad extrapatrimonial deben hacerse cargo de la forma en que se ejercen los derechos fundamentales de los infantes, adolescentes y ancianos, excluyéndose la aplicación automática de las reglas de la representación legal.

${ }^{4}$ Barcia (2002), pp. 445-478.

${ }^{5}$ BARCIA (2011), pp. 21-40.

${ }^{6}$ La referida ley solo estableció un ilusorio cuidado compartido, en el nuevo artículo $225.1^{\circ}$ y $2^{\circ}$ del $C C c h$. A diferencia de lo que sucede en el Derecho Comparado, en países como España, Italia, Francia, las facultades y derechos compartidos se han materializados en figuras específicas como titularidad y ejercicio conjunto de la patria potestad en España, custodia compartida en Italia y Estados Unidos, o autoridad parental conjunta como en Francia. BARCIA (2013a), pp. 30-40.

${ }^{7}$ Esto se puede apreciar al revisar la discusión en torno a la igualdad de los hijos -en la LF- o las posiciones que se mantuvieron en torno a la consagración del divorcio desvincular en la LMC de 2004. Los argumentos son absolutamente circulares y rara vez se recurre al Derecho Comparado como debiera hacerse en esta clase de discusiones. 
El atraso más evidente se presenta tanto en la regulación de la demencia y la falta de protección de los ancianos como en lo relativo a la infancia y adolescencia. En el fondo, las reglas del Código Civil de Andrés Bello tienen el gran problema que consideran al individuo como sujeto de derechos patrimoniales, es decir, tiene una concepción de la capacidad que se centra en el contrato. No es casualidad que esta concepción patrimonialista del ser humano trate a la capacidad como un requisito del contrato. El trabajo, que les presento, se centra en la ancianidad y las líneas precedentes explican por sí solas la importancia del tema que se está analizando, pero su elección tiene un segundo sustento que es más humano, más personal.

\section{UnA Distinción Fundamental EN EL DeRecho Civil Moderno: CAPACIDAD PATRIMONIAL Y EXTRAPATRIMONIAL}

La capacidad patrimonial se sustenta básicamente en las obligaciones, los bienes y los contratos. Por ello es que los conceptos 'estado civil', 'capacidad' y 'patrimonio', están relacionados de manera íntima en la teoría clásica del Derecho ${ }^{8}$. En el Derecho clásico, los derechos extrapatrimo60 niales son ignorados o se confunden con los patrimoniales e, incluso, el ejercicio de aquellos se supedita a $\operatorname{estos}^{9}$. Esta tendencia a expulsar del

${ }^{8}$ La teoría clásica del patrimonio, que fuera levantada por Charles Aubry y Charles Rau, hace ingentes esfuerzos para separar los conceptos de capacidad y patrimonio. Según las tesis que se denominarían como subjetivas, el patrimonio se encuentra estrechamente vinculado con la personalidad, siendo aquel una emanación de esta. En este sentido el patrimonio sería una emanación del poder jurídico de la persona. Pero la teoría clásica no concibe al patrimonio como un conjunto de derechos y obligaciones, sino como la aptitud para adquirir esos derechos y obligaciones. Para la teoría clásica, el patrimonio es una universalidad jurídica, compuesta por todos los derechos y obligaciones, apreciables en dinero, que tienen por titular a una misma persona. Marcel Planiol agregaría que una persona a pesar de poseer muy pocas cosas e, incluso, ninguna, tiene patrimonio. El patrimonio, dentro de esta concepción, es un continente distinto de su activo o pasivo y el contenido es variable en cantidad y calidad, pero el patrimonio en sí mismo no cambia nunca. Sin embargo, estas teorías no pudieron sobrevivir a la crítica de artificialidad por cuanto el señalar que una persona sin bienes tiene patrimonio -si por este se entiende un conjunto de bienes evaluables, no deja de ser solo un artilugio. Tampoco estas teorías son capaces de explicar la extensión de los derechos del individuo después de su fallecimiento.

${ }^{9}$ Ello se puede apreciar fácilmente en la relación entre capacidad y estado civil. A este respecto podemos dar dos definiciones de estado civil. El primero es el que nos da el artículo $304 \mathrm{del} C C \mathrm{ch}$ y el segundo, es el sostenido por Manuel Somarriva. Dicho autor define al estado civil indicando que es "el lugar permanente de una persona dentro de la sociedad que depende principalmente de sus relaciones de familia y que la habilitan para ejercitar ciertos derechos o contraer ciertas obligaciones civiles”. De la definición 
Derecho Civil al Derecho de las Personas, nos señalaba Federico De Castro, es deudora de Friedrich Karl von Savigny, para quien el Derecho Civil basado en la persona, que tenía su sustento en la distinción de Gayo entre Derecho de cosas y personas, era "carente de todo mérito intrínseco". De este modo, propugnaba desechar la clasificación de Gayo, de Derecho de Cosas y Personas, y adoptar la distinción cuatripartita -que califica como científica- de Derecho de Cosas, de Obligaciones, de Familia y Sucesorio $^{10}$. Esta tendencia sería la que se habría impuesto en las distintas Facultades de Derecho. Esta posición, un tanto rupturista, se explica por las siguientes dos causas:

- La primera es histórica y obedece a que el Derecho de la Persona supone ciertos consensos, que no se genera en todos los tiempos y sociedades -no debemos olvidar que Europa aún estaba traumatizada por las guerras religiosas de los siglos XVI y XVII-.

- La segunda causa es la constitución del sistema jurídico-burgués, o, si se quiere, el advenimiento de la Ilustración.

La Ilustración da lugar a lo que nosotros hemos denominamos Derecho Civil clásico. Dicho Derecho es libertario por cuanto supone el término del antiguo régimen, y da lugar a un derecho basado en la economía, en-

precedente se puede apreciar que el estado civil requiere de los dos siguientes elementos constitutivos:

a) La pertenencia social a un grupo determinado, o familia.

b) Dicha pertenencia al grupo genera ciertos derechos y obligaciones, como podría ser la filiación que genera un deber de alimentos.

Así, podemos apreciar la íntima relación entre capacidad y estado civil y apreciar una tendencia a explicar el funcionamiento del Derecho Civil exclusivamente a través de categorías patrimoniales.

El último elemento de la definición de estado civil ha sido objeto de fuertes críticas por la doctrina, señalándose que dicho concepto atiende más bien a la capacidad de ejercicio. A pesar de que estas críticas se han enfrentado, ello es sintomático de la relación entre estado civil y capacidad.

La doctrina que enfrenta esta crítica, como Ramón Meza B., señala que el estado civil vincula a un individuo con la sociedad, es decir, se trata de un vínculo externo a los sujetos; en cambio la capacidad de ejercicio atiende al individuo en sí mismo. SOMARRIVA (1995), p. 584 y Meza (1995), pp. 191-192.

${ }^{10}$ Esta tendencia se aprecia aún en el Code que, en su libro primero "De las personas", regula casi exclusivamente el Derecho de Familia. Como se desprende de lo señalado por Federico de Castro, estas tesis lo que hacían en definitiva era expulsar al Derecho de las Personas del Derecho Civil. Una de las manifestaciones de esta tendencia es la que pretende regular los derechos de la persona, solo en el ámbito constitucional. En resumen, la persona humana es sólo un "presupuesto normal de derechos subjetivos y obligaciones”. Esta tendencia sería suscrita por Friederich Karl von Savigny, Ferdinan Regelsberg, Bernard Windscheid, Heinrich Dernburg y Immanuel Bekker, y fomentada básicamente por la pandectista alemana, y pasaría a todos los códigos modernos. DE Castro y Bravo (1952), pp. 13-17. 
tendida como una ciencia de lo escaso. En cambio, el Derecho moderno, aunque es el Derecho de la abundancia, responde a los horrores de la Segunda Guerra Mundial ${ }^{11}$. Esta diferencia dará lugar a unos sistemas jurídicos sustentados sobre los derechos fundamentales, los que desplazaran a un derecho basado en una economía de la escasez. Lo que se pretende es volver sobre la categoría de Gayo para fijar los límites entre el Derecho de cosas -que está determinado en la actualidad por el funcionamiento del mercado- y el Derecho de Personas, que se sustenta en los derechos fundamentales. Uno de los campos en que se diferencian estos estatutos es el de la capacidad de ejercicio.

Los sustentos ideológicos de la capacidad en el Derecho clásico tienen que ver con el reconocimiento del ser humano, como sujeto independiente, en relación con el poder público y específicamente, en el mercado, como un sujeto capaz de tomar sus propias decisiones, sin la tutela del Estado o de terceros. Una manifestación de ello es la redacción de nuestro artículo 55 del $C C$ ch, según el cual: "son personas todos los individuos de

${ }^{11}$ No es de extrañar que las tesis que sustenta los derechos fundamentales, y su influencia sobre el Derecho Privado, se comenzaran a desarrollar fuertemente en la Alemania de pos Segunda Guerra Mundial. Y ello se debió a la conciencia de los horrores 62 de la violación de los derechos fundamentales por el nazismo en el holocausto. Una de las sentencias que daría la partida al desarrollo de los derechos de la personalidad, desde la perspectiva de los derechos fundamentales, y como límite al Derecho Patrimonial sería la famosa sentencia del TC alemán en el caso Lüth (BVerfGE 7, 198). Dicha sentencia resolvió: "2. En el derecho civil se desarrolla indirectamente el contenido legal de los derechos fundamentales a través de las disposiciones de derecho privado. Incluye ante todo disposiciones de carácter coercitivo, que son realizables de manera especial por los jueces mediante las cláusulas generales. 3. El juez civil puede violar con su sentencia derechos fundamentales ( $\$ 90$ BVer-GG), cuando desconoce los efectos de los derechos fundamentales en el derecho civil. El Tribunal Constitucional Federal examina las sentencias de los tribunales civiles sólo por violaciones a los derechos fundamentales, pero no de manera general por errores de derecho. 4. Por disposiciones de derecho civil también pueden entenderse las 'leyes generales' en el sentido del art. 5, párrafo 2 de la Ley Fundamental, y pueden limitar los derechos fundamentales a la libertad de opinión. 5. Las 'leyes generales' para el Estado democrático libre deben ser interpretadas a la luz del especial significado del derecho fundamental de la libertad de opinión. 6. El derecho fundamental del art. 5 de la Ley Fundamental protege no sólo la expresión de una opinión como tal, sino también, los efectos espirituales que se producen a través de la expresión de una opinión. 7. La expresión de una opinión, que contiene un llamado a un boicot, no viola necesariamente las buenas costumbres en el sentido del $\S 826$ del $B G B$; puede estar justificada constitucionalmente mediante la libertad de opinión al ponderar todas las circunstancias del caso”. Lüth (1958).

La tesis rupturistas también se manifiestan modernamente en conocidas tesis como la de Cicu, que plantearían que las áreas del derecho civil extrapatrimonial, como el derecho de personas y de familia, fuesen abordadas por el Derecho Público, y no por el derecho privado. DíEz-PiCazo (1989), p. 38. 
la especie humana, cualquiera que sea su edad, sexo, estirpe o condición (...)”. En estos términos Juan Marín nos señala:

"para el Derecho, la persona es, más que un centro de imputación de normas jurídicas (como gusta definir a los positivistas), un ser humano con valores propios merecedor de respeto y de tutela"12.

Dentro de los valores del Código está la libertad, entendida como libertad negativa, pero el Derecho moderno agregaría la libertad positiva, es decir, el respeto y desarrollo de los derechos fundamentales.

En cuanto al Derecho Civil, a pesar de que no cabe confundir los derechos de la personalidad con los extrapatrimoniales -por cuanto los derechos de la personalidad pueden ser de ambas clases- ${ }^{13-14}$; está claro que los de la personalidad, en el Derecho moderno, se centran en los fundamentales. Para darse cuenta de ello basta con señalar que los modernos derechos extrapatrimoniales son el derecho a la honra y a la intimidad, derecho a la identidad y la propia imagen, derecho a la integridad del propio cuerpo, las libertades en general (derechos de actuación contra el Estado o los particulares), etc., es decir, todos pueden ser abordados como derecho fundamentales, desde la perspectiva del Derecho Público ${ }^{15}$, o como derechos extrapatrimoniales, desde la perspectiva del Derecho Privado ${ }^{16}$.

${ }^{12}$ Marín (1996), p. 58.

${ }^{13}$ Larroumet (2006), pp. 298-299.

${ }^{14}$ Por cuanto es perfectamente posible violar un derecho patrimonial, tanto derecho fundamental, como se aprecia de nuestra jurisprudencia en el recurso de protección.

${ }^{15}$ Como destaca Enrique Ramos Chaparro no han sido pocos los esfuerzos por los ius publicistas de fundamentar la creación de derechos fundamentales ejecutables, al modo de los derechos subjetivos. El esfuerzo aleja a estos derechos de meras declaraciones programáticas de principios para oponerlos, primero, al Estado (y luego a los propios particulares). El esfuerzo también pasa por considerar que ellos determinan de forma orgánica la aplicación de las normas (supra sistema de interpretación constitucional). Naturalmente, los derechos de la ancianidad pueden abordarse desde esta perspectiva y se aplicarían con eficacia directa e indirecta. Esta visión, aunque es de una relevancia fundamental, excede el presente trabajo. Ramos (1995), pp. 157-174

${ }^{16}$ Estas tesis que son una respuesta al Derecho clásico -eminentemente patrimonialistatambién deben revisarse, porque los derechos de la personalidad dan lugar no solo a derechos extrapatrimoniales sino, también, a derechos patrimoniales. Federico de Castro nos advierte sobre este peligro, señalando: "la persona, cuando se estudia en la Parte general, reducida a la abstracción de sujeto de derechos, tomara cuerpo y color con cada uno de los derechos subjetivos; si se le considera como parte del Derecho de familia, insensiblemente se olvidarán los principios de libertad y propia responsabilidad; en fin, si se estima a la persona como un elemento de los negocios jurídicos, las ideas de protección de los incapaces y las de la propia determinación se verán sacrificados antes los de seguridad jurídica y rapidez del tráfico (hay nota al pie)" (el paréntesis y en cursiva es mío). 
A igual conclusión se puede llegar si se analizan los grandes conflictos jurídicos que se generan en la actualidad. Ello se refleja en las discusiones que tenemos en el Derecho Civil moderno, como el matrimonio entre personas del mismo sexo; la igualdad de los padres respecto de los hijos y la igualdad entre los propios hijos en cuanto a su origen; la procedencia de la indemnización de perjuicios por incumplimiento de deberes extrapatrimoniales, etc. ${ }^{17}$. Los límites a estas capacidades tiene que ver con lo que socialmente se considera como "bueno" (los casos más radicales permiten entender este fenómeno). En un comienzo se discute si cierta capacidad natural que antes no existía atenta contra los principios de convivencia, que nos damos en sociedad como, por ejemplo, sucede con el aborto, la eutanasia, la eugenesia, el cambio de sexo, etc. Luego, cuando la sociedad permite la titularidad de estos derechos impide que ellos sean ejercidos a través de la representación legal. Así, la tendencia criticada en este trabajo, es decir, aquella por la cual se entienden los derechos extrapatrimoniales, a través de los derechos patrimoniales, ha sido dejada de lado hace años en el Derecho Comparado, por cuanto la representación legal no se aplica a estos $\operatorname{casos}^{18}$.

Los derechos patrimoniales se siguen sustentando, en gran medida, en la teoría clásica del Derecho. Ello se debe a que los derechos patrimonia64 les, personales y reales, reflejan básicamente relaciones de intercambio, ya sea de forma dinámica, como en los contratos, o estática, a través del reconocimiento y protección de la propiedad. La diferenciación entre estas áreas del Derecho Privado se aprecia en el sustento teórico de los derechos patrimoniales y extrapatrimoniales. El concepto fundamental, en la capacidad extrapatrimonial, dejando de lado la teoría clásica, no es el patrimonio, sino la dignidad del ser humano ${ }^{19} \mathrm{y}$, por ende, consideraciones netamente patrimoniales,sustentadas en el patrimonio, no sirven

La advertencia de Federico DE CASTRO, aplicada en la actualidad, nos lleva a tener cuidado en analizar solo a los derechos fundamentales, como Derecho Público o constitucional, o a los derechos extrapatrimoniales, solo como Derecho Privado o Civil. DE Castro y Bravo (1952), p. 18.

${ }^{17}$ Los problemas que debemos enfrentar en el futuro son igualmente interesantes: la biogenética (eugenesia), medicina regenerativa, niñez y cambio de sexo, visitas de los convivientes a los hijos de su ex pareja, derechos reproductivos de las personas del mismo sexo, etcétera.

${ }^{18}$ Sin perjuicio de lo cual, ello no quiere decir que la tendencia imperante no sea objeto también de críticas por tratar de homogeneizar realidades diferentes a través de los derechos fundamentales.

${ }^{19}$ Esta es la opinión de Gonzalo Figueroa para el cual "el concepto de dignidad de todas las personas es la base de los conceptos de igualdad, no discriminación y libertad". Figueroa (2011), p. 29. 
para deslindar, ni definir estos derechos ${ }^{20}$. Estos derechos, si bien tienen repercusiones patrimoniales, se sustentan en consideraciones que no se desprenden de las relaciones patrimoniales, sino en consideraciones éticas o morales o, sí se quiere, de orden superior. Incluso, algunos autores discuten si la ancianidad, dado su alto impacto, debe ser tratada como una rama independiente del Derecho Privado, como lo es el Derecho de la Infancia ${ }^{21}$.

La capacidad patrimonial obedece a la reglas generales del Código Ci$v i \ell^{2}$, y tal vez ella se ve reflejada de forma especial en la infancia en la cual la patria potestad -que da lugar a la representación legal de los padres- se le otorga un contenido patrimonial, como se desprende principalmente de la definición de patria potestad del artículo $243 \mathrm{del} C C \mathrm{ch}^{23}$. No podría ser de otra forma por cuanto los padres no pueden representar a sus hijos en

${ }^{20}$ En este sentido, Gonzalo Figueroa no puede ser más pertinente cuando nos señala que: [e]l segundo aspecto tiende a exceder la concepción meramente patrimonial de la persona (sujeto de derechos titular de un patrimonio compuesto por bienes y deudas apreciables en dinero, según la concepción de la escuela subjetiva del patrimonio), para abarcar también derechos extrapatrimoniales, que no admiten apreciación pecuniaria. La persona natural se define, así, más por sus intereses y características vitales, espirituales y morales, que por sus rasgos económicos y patrimoniales”. FigueroA (2011), p. 19.

${ }^{21}$ Kemelmajer (2006), pp. 43-44.

${ }^{22}$ La capacidad patrimonial concebida desde la perspectiva clásica, como destaca Enrique Ramos, ha sido también objeto de duras críticas, de autores como Jakob Burckhardt, Ernst Rudolf Bierling, Edmun Husserl y Karl Larenz. El caso típico de esta crítica consiste en preguntarse cómo operan los incapaces no representados. Así nos podemos preguntar, siguiendo a Enrique Ramos, qué ocurre con los actos de los empleados de un establecimiento comercial que es propiedad de un menor que no tiene representante legal. La respuesta a preguntas de esta clase exigen recurrir a la concepción que el Derecho tiene de los derechos fundamentales. Naturalmente, entre nosotros, se podría recurrir a la agencia oficiosa, o en el Derecho español a la accesión como modo de adquirir; pero a diferencia de Enrique Ramos la respuesta a este problema debe buscarse en los derechos fundamentales de la infancia, como podría ser una aplicación restrictiva del principio del interés superior del niño. Las categorías como agencia oficiosa, accesión, etc. tienen que ver con la generación de riqueza y la determinación de las reglas a través de las cuales opera el mercado; sin embargo, la solución a problemas, como el planteado, debe combinar el funcionamiento del mercado - protección de los acreedores, trabajadores, etc.- con la protección de la infancia en el caso de menores desvalidos. Así, la categoría persona-valor, a que se remite Pietro Perlingieri como integrante de lo que podemos denominar Escuela realista italiana de la capacidad, se construye sobre conceptos superiores a la distinción entre capacidad de goce y ejercicio, como lo es la dignidad del ser humano. Ramos (1995), pp. 196-197 y 199-202.

${ }^{23}$ Las guardas, que excluyen la patria potestad, en cambio, comprenden ambos ámbitos, patrimonial y extrapatrimonial. Sin embargo, la preocupación fundamental del Código, es el ámbito patrimonial como se desprende de la figura del curador adjunto. El curador adjunto, establecido en el ex art. $344 \mathrm{del} C C \mathrm{ch}$, tiene una administración separada respecto del representante legal del hijo, en el caso de la patria potestad, o del pupilo en las guardas, cuando los intereses de ambos sean contrapuestos. 
materia de ejercicio de derechos extrapatrimoniales, y fundamentales ${ }^{24}$. Este fenómeno, como se pondrá de manifiesto en el presente trabajo, también se produce a propósito de la ancianidad. En la infancia el ejercicio de los derechos extrapatrimoniales es personalísimo, es decir, no admiten representación como también ocurre en materia de ancianidad. Otro aspecto fundamental que la capacidad extrapatrimonial reconoce, a diferencia de la patrimonial, es la capacidad e incapacidad progresiva. En materia patrimonial, por las seguridades del tráfico, las personas son capaces o incapaces de acuerdo con parámetros absolutos, como la edad respecto de los menores, o la demencia, en relación con los ancianos. En cambio, en el campo extrapatrimonial las categorías absolutas son dejadas de lado para recurrir, en materia de infancia, al ejercicio progresivo de los derechos de la infancia y de la mayor autonomía posible, a propósito del adulto mayor. La situación del adulto mayor está íntimamente ligada con la discapacidad, pero no entendida de forma absoluta por cuanto ella puede operar de forma gradual.

La distinción precedente, entre capacidad patrimonial y extrapatrimonial, es fundamental y radica en la diferencia entre el mercado, como asignador de recursos, y los derechos fundamentales, como un criterio superior, en el ejercicio de derechos y como una razón delimitadora del mercado. No

66 es del caso ahondar sobre este fenómeno, que tiene más aristas de las que es factible imaginar; pero es fácil notar que nos estamos refiriendo a dos derechos en los que se actúa conforme a premisas diferentes, y en ambos el sujeto de derecho, es decir, la persona, es el principal actor. La forma en que se concretizan estos derechos fundamentales o derechos de la personalidad para el Derecho Privado, son relevantes por cuanto naturalmente inciden en la concepción que nuestra propia sociedad tiene del ser humano. A continuación, antes de entrar a analizar la ancianidad, se abordará una de las figuras a través de las cuales el Derecho Civil se refiere a ella: la incapacidad.

\section{UNA CUESTIÓN TERMINOLÓGICA: ¿INCAPACIDAD O INCAPACITACIÓN?}

En España se distingue entre incapacidad para referirse a la incapacidad natural, por la que un acto puede ser anulado si se acredita la falta de capacidad de una de las partes que lo celebra, para diferenciarla de la

${ }^{24}$ Aun en el Código decimonónico de Andrés Bello, el ejercicio de derechos extrapatrimoniales no admiten representación legal, como ocurre con el matrimonio, reconocimiento de un hijo, el otorgar un testamento, etc. No me extiendo en este punto por cuanto, ya lo he desarrollado anteriormente. BARCIA (2006), pp. 137 a 158 y (2013b), pp. 3-52. 
incapacitación a la que se da lugar, por regla general, mediante decreto judicial $^{25}$. La distinción es relevante para los efectos que estamos analizando por cuanto la incapacitación, que entre nosotros se genera por aplicación del decreto de interdicción, suele aplicarse conforme a consideraciones netamente patrimoniales. Por lo que la actuación, a través de la representación legal por estar vedada para los actos extrapatrimoniales, requiere de un pronunciamiento judicial expreso, no siendo suficiente la representación legal. A continuación se ahondará en este análisis.

La incapacidad ha sido una de las materias que menos modificaciones ha recibido en nuestro Derecho, salvo en lo relativo al sordomudo, que no se puede dar a entender de forma clara ${ }^{26}$, y la derogación de la incapacidad relativa de la mujer casada en sociedad conyugal. De este modo, hace falta una revisión profunda de la regulada en estatutos cerrados, propios del ejercicio de derechos patrimoniales ${ }^{27}$. Alguna doctrina comparada ha

${ }^{25}$ En este sentido Luis Díez Picazo nos señala: "la incapacitación es un estado civil de la persona física que se declara judicialmente cuando concurre en ella alguna de las causas establecidas por la ley”. Dítz-Picazo y Gullón (1998), p. 246 y Zurita (2012), pp. 14-15.

${ }^{26}$ Esta incapacidad antes de la reforma de la ley $\mathrm{N}^{\circ} 19.904 / 2003$, de 3 de octubre de 2003, se refería a los sordomudos que no pueden darse a entender por escrito. En este sentido se reformaron los artículo $4.1^{\circ}, \mathrm{n}^{\circ} 4$ de la antigua LMC.

La nueva LMC en su artículo $5.1^{\circ}, \mathrm{N}^{\circ} 5$ establece: "no podrán contraer matrimonio: Los que no pudieren expresar claramente su voluntad por cualquier medio, ya sea en forma oral, escrita o por medio de lenguaje de señas".

Tal vez la única materia en que el Derecho se refiere al sordomudo, que no puede expresarse por escrito, es el actual artículo $13.2^{\circ}$ de la LMC. Dicha norma exige a propósito de estas personas que la manifestación, información y matrimonio se haga por medio de persona habilitada para interpretar la lengua del o los contrayentes o que conozca el lenguaje de señas.

${ }^{27}$ Ello se evidencia si se compara nuestro sistema de incapacidades con el que predomina en la mayoría de los ordenamientos jurídicos. De este modo, por indicar solo algunos ejemplos, Mercedes Heredia y Cristóbal Fábrega señalan a cerca de de la antigua regulación de la demencia en el Código Civil español de 1889: "el sistema de protección de los incapaces establecido en nuestro Código Civil de 1889 partía del error de incluir en el concepto de dementes, con similitud de efectos tutelares, a una multitud de enfermos de características muy diferentes -a grandes rasgos podemos hablar de deficiencia, enfermedad mental y senilidad-y necesitados, por ello, de campos de protección diferentes". Y Cristina de Amunátegui nos indica, respecto de la reforma española de 1983: "frente a la rigidez del sistema anterior el nuevo modelo posibilita lo que se ha llamado una incapacitación a medida de la persona, que debe construir el juez en la sentencia teniendo en cuenta sus circunstancias específicas. Ese diseño a medida debe referirse esencialmente a dos extremos: determinar la sumisión del incapaz a tutela o a curatela atendiendo a su grado de discernimiento; $y$, con independencia de lo anterior, matizar en cada caso su esfera de capacidad, determinando tanto los actos que pueda realizar él sólo, como especificando igualmente aquellos para los que necesitará de la actuación del tutor supliendo su voluntad, o del curador completando la misma".

La legislación española ya reseñada, que es muy superior a la regulación que de la incapacitación se hace en el Derecho chileno, no estuvo exenta de críticas. Y, en este sentido, 
llegado, incluso, a entender la capacidad como un derecho fundamental. Estos planteamientos ponen su acento en la limitación de los efectos radicales de la incapacitación. Por ello se ha estimado que en principio la incapacitación no afectaría al ejercicio de derechos fundamentales ${ }^{28}$. Una manifestación de ello es que la representación, en cuanto a los derechos extrapatrimoniales, no opera de la misma manera que en el Derecho patrimonial; incluso es dudoso que la representación legal de los incapaces tenga cabida en el campo de los derechos extrapatrimoniales ${ }^{29}$. También es una consecuencia de ello que los procesos de interdicción tengan un eminente carácter garantistas. Así, el juez, en nuestro Derecho, sobre todo en lo que respecta al demente, solo puede incapacitar a una persona con trastornos mentales, a través del decreto de interdicción. Lamentablemente, esta garantía se ha visto afectada por las leyes $\mathrm{N}^{\circ} 20.422$ y $\mathrm{N}^{\circ} 18.600^{30}$. La primera de ellas establece que los organismos que pueden calificar la discapacidad son COMPIN e instituciones públicas o privadas reconocidas para estos efectos por el Ministerio de Salud. El proceso de calificación debe asegurar una atención interdisciplinaria y que el organismo que certifica la discapacidad es únicamente la COMPIN correspondiente. Pueden solicitar

la autora precedentemente nos trae a colación una sentencia del Tribunal Supremo español, que resuelve: "la inquietud que subyace en toda la posición social de la demandada es la repulsa a una determinada tutela; es decir, no tanto parece oponerse a la incapacitación, sino a las medidas de guarda y protección de su persona; expresa que su estado físico y mental no perjudicará su patrimonio pues ha adoptado medidas. Pero la incapacitación es un estado civil indisponible, regulado por normas de ius cogens, que se refieren a la persona y al patrimonio y que da lugar al sistema de guarda que en este caso es la tutela y, ésta, tras la Ley 13/1983 de reforma del Código Civil, es una tutela de autoridad, que se constituye y controla judicialmente”. Heredia y Fábrega (1998), p. 15 y De Amunátegui (2006), pp. 2-9.

${ }^{28}$ BARRAnco et al. (2012), pp. 57-58 y 61-63.

${ }^{29}$ Juan Andrés Varas analiza cómo los jueces podrían resolver en casos de ejercicio de derechos extrapatrimoniales, en que no cabe la representación legal automática de los padres. VARAS (2009), pp. 353-356.

${ }^{30}$ Esta última ley establece, en su art. 18 bis, inc. $3^{\circ}$ ley $\mathrm{N}^{\mathrm{o}} 18.600$ : "la curaduría provisoria durará mientras permanezcan bajo la dependencia y cuidado de las personas inscritas en el Registro aludido y no se les designe curador de conformidad con las normas del Código Civil”. Es lógico pensar que la curatela a la que se refiere esta norma es la que corresponde al demente. $\mathrm{Y}$ el art. 18 bis de la ley $\mathrm{N}^{\mathrm{o}} 18.600$ agrega que, si se cumplen ciertos requisitos, las personas naturales o jurídicas que se encuentren inscritas en el Registro Nacional de Discapacidad y que tengan a su cargo personas con discapacidad mental, cualquiera sea su edad, serán curadores provisorios de los bienes de estos, por el solo ministerio de la ley (art. 18 bis inc. $1^{\circ}$ ley $\mathrm{N}^{\mathrm{o}}$ 18.600). La Contraloría General de la República ha señalado que dentro de las personas naturales que menciona la disposición pueden estar los parientes del discapacitado: "como se puede apreciar, la norma citada no establece limitaciones en cuanto a quienes pueden inscribirse como personas naturales en el mencionado Registro, por lo que debe entenderse que dicha expresión también comprende a los parientes del discapacitado mental" (dictamen $\mathrm{N}^{\circ} 1449$, de 14 de enero de 2003). 
la calificación y certificación de la discapacidad, el interesado, las personas que lo representen o las personas o entidades que lo tengan a su cargo. La calificación debe realizarse dentro del plazo de veinte días hábiles contados desde solicitud y la certificación de la discapacidad dentro de los cinco días siguientes a la fecha de calificación. Una vez certificada la discapacidad, los antecedentes serán enviados por la COMPIN al Registro Civil para la inscripción en el Registro Nacional de Discapacidad. A su vez, el artículo 18 bis de la ley $\mathrm{N}^{\circ} 18.600$, dispone que las personas naturales o jurídicas que se encuentren inscritas en el Registro Nacional de la Discapacidad y que tengan a su cargo personas con discapacidad mental, cualquiera sea su edad, serán curadores/as provisorios/as de los bienes de estos, por el solo ministerio de la ley, siempre que se cumplan los siguientes requisitos:

a) Que se encuentren bajo su cuidado permanente, lo cual se entiende que se cumple:

i Cuando existe dependencia alimentaria, económica y educacional, diurna y nocturna; $y$,

ii Cuando dicha dependencia es parcial, es decir, por jornada, siempre y cuando ésta haya tenido lugar de manera continua e ininterrumpida, durante dos años a lo menos.

b) Que carezcan de curador/a o no se encuentren sometidos a patria potestad.

c) Que la persona natural llamada a desempeñarse como curador/a provisorio/a o, en su caso, los representantes legales de la persona jurídica, no estén afectados por alguna de las incapacidades para ejercer tutela o curaduría.

La crítica a este sistema es evidente por cuanto este podría prestarse para abusos. Es verdad que nuestro ordenamiento jurídico consagra un sistema de recursos constitucionales, que permitiría enfrentar eventuales abusos, pero es muy probable que los afectados no tengan acceso a estos mecanismos.

\section{LA ANCIANIDAD y el DeRecho Civil}

El somero análisis que se hace a continuación, pretende evidenciar la falta de regulación del fenómeno de la ancianidad no desde un prisma asistencial, sino desde una concepción moderna de la capacidad. Y ello es grave por cuanto lo que no se está respetando es la autonomía de los adultos mayores para poder hacer frente a una futura incapacidad ${ }^{31}$.

${ }^{31}$ Ello se logra en España a través de los denominados "poderes preventivos". Para Cristina de Amunátegui, en el orden temporal, estos poderes pueden ser de dos clases: los que se celebran antes de la incapacidad y los que se otorgan para ser ejercidos al momento de la incapacidad. De Amunátegui (2008), p. 228. 


\title{
1. La regulación de la ancianidad en Chile
}

\author{
En Chile recién el año 2002, mediante la ley $\mathrm{N}^{\circ} 19.828$ se crea el SENAMA, \\ que conforme al artículo 1 de la referida ley: \\ “...velará por la plena integración del adulto mayor a la sociedad, \\ su protección ante el abandono e indigencia, y el ejercicio de los \\ derechos que la Constitución de la República y las leyes le reco- \\ nocen" 32 .
}

Esta regulación se ocupa de los ancianos vulnerables, más que de los derechos de la ancianidad ${ }^{33}$. Las personas mayores en Chile no disponen de una ley específica para hacer valer sus derechos. Los derechos del adulto mayor sólo se regulan a raíz de derechos económicos y sociales; pero no como derechos de la personalidad, desde la perspectiva del Derecho Civil ${ }^{34}$.

${ }^{32}$ En varios países de nuestro entorno se establecen consejos rectores para la formulación y aplicación de políticas públicas, como Costa Rica (Consejo Nacional de la Persona Adulta Mayor), El Salvador (Consejo Nacional de Atención Integral a los Programas de los Adultos Mayores), Guatemala (Consejo Nacional para la Protección a las Personas de la Tercera Edad y el Comité Nacional de Protección a la Vejez, que actúa como asesor del primero), México (Consejo Ciudadano de Adultos Mayores) y la República Dominicana (Consejo Nacional de la Persona Envejeciente), entre otros.

${ }^{33}$ Uno de los programas que protege a los adultos mayores vulnerables es el Programa de Viviendas Protegidas para Adultos Mayores, regulado en el decreto $\mathrm{N}^{\circ}$ 49/2011 del Ministerio de Planificación. En el Derecho Comparado se pueden encontrar figuras como ésta en la ley $N^{0}$ 41/2003, de 18 de noviembre, sobre Protección Patrimonial de las Personas (España). A ella se suman una serie de modificaciones a la Ley de Enjuiciamiento Civil (CPC), Ley del Registro Civil, normativa tributaria, etc., tendientes a proteger a los ancianos vulnerables. En todo caso, la más reciente de ellas es la denominada Ley de Dependencia, que se produce por el real decreto $\mathrm{N}^{\circ} 1.856 / 2009$, de 4 de diciembre, por el que se regula el procedimiento para el reconocimiento, declaración y calificación del grado de discapacidad. El Derecho alemán ha modificado la regulación de la ancianidad en numerosas oportunidades (1990, 1998 y 2005). En Italia la ley $\mathrm{N}^{\circ} 6$ del 2004 establece la figura del l'amministrazione di sostegno como medida de protección de la ancianidad. Dicha regulación trata de extender lo más posible la capacidad de ejercicio de los adultos mayores, sobre todo en aspectos no patrimoniales relacionados con lo cotidiano.

Lo que configura estas regulaciones es la tensión entre la autonomía en las decisiones, que debe respetarse a los ancianos, y su protección frente a abusos o frente a la pérdida de su capacidad.

${ }^{34}$ En el ámbito europeo se puede destacar la protección de la ancianidad que promueve el artículo $34.1^{\circ}$ de la Carta de los Derechos Fundamentales de la Unión Europea, que establece lo siguiente: "la Unión reconoce y respeta el derecho de acceso a las prestaciones de seguridad social y a los servicios sociales que garantizan una protección en casos como (...) la dependencia o la vejez (...) según las modalidades establecidas por el Derecho de la Unión y las legislaciones y prácticas nacionales". También es especialmente relevante la Declaración de Principios del Consejo de la Unión Europea y de los Ministros de Asuntos 
El centrar a la ancianidad en los derechos económicos y sociales, o respecto de ancianos vulnerables ha sido la tendencia general en el ámbito internacional. Así, se puede consultar, en el ámbito internacional, la Declaración Universal de Derechos Humanos de 1948 (art. 25.1 ${ }^{\circ}$ ); la Convención Americana sobre Derechos Humanos de 1969 (art. 16), también se centra en el derecho a la seguridad social; la Primera Asamblea Mundial sobre el Envejecimiento de Viena en 1982, adoptó el Plan de Acción Internacional sobre el Envejecimiento, que reúne sesenta medidas en materias de carácter socio-sanitario; el Protocolo Adicional a la Convención Americana sobre Derechos Humanos en materia de derechos económicos, sociales y culturales de 1988, se preocupa especialmente de la protección de los ancianos en el artículo $17^{35}$; II Plan de Acción Internacional sobre el Envejecimiento (Segunda Asamblea Mundial sobre el Envejecimiento el año 2002) de Madrid pone de relieve de manera exclusiva aspectos relacionados con la protección de la vejez ${ }^{36}$; Estrategia regional de implementación para América Latina y el Caribe del Plan de Acción Internacional de Madrid sobre el Envejecimiento (2003), de la CEPAL; la Declaración de Brasilia de la Segunda Conferencia Regional Intergubernamental sobre Envejecimiento en América Latina y el Caribe: "Lineamientos para una convención de los derechos de las personas mayores/de edad" (2007) ${ }^{37}$; V Cumbre de las Américas, Declaración de

Sociales, de 6 de diciembre de 1993, que dispone la plena ciudadanía de personas de edad avanzada en cuanto a libertad e igualdad de derechos y deberes en todos los ámbitos de la vida social, se proclama la lucha contra la exclusión y el aislamiento social y se consagra como principio fundamental de esta política comunitaria, el de la solidaridad entre generaciones $\left(\operatorname{art} .9 .1^{\circ}\right)$.

${ }^{35}$ Esta disposición establece que toda persona tiene derecho a protección especial durante su ancianidad y que los Estados partes se comprometen a adoptar de manera progresiva las medidas necesarias a fin de llevar este derecho a la práctica y en particular a: (a) proporcionar instalaciones adecuadas, así como alimentación y atención médica especializada a las personas de edad avanzada que carezcan de ella y no se encuentren en condiciones de proporcionársela por sí mismas; (b) ejecutar programas laborales específicos destinados a conceder a los ancianos la posibilidad de realizar una actividad productiva adecuada a sus capacidades respetando su vocación o deseos; (c) estimular la formación de organizaciones sociales destinadas a mejorar la calidad de vida de los ancianos.

${ }^{36}$ Naciones Unidas (2003).

${ }^{37}$ Una de las declaraciones más relevantes de esta declaración de la CEPAL es aquella por la cual se señala: "reconociendo que el envejecimiento es uno de los mayores logros de la humanidad, que en América Latina y el Caribe la población ha ido envejeciendo de manera heterogénea y que en algunos países el proceso está más avanzado que en otros y en consecuencia los desafíos en términos de adecuación de las respuestas del Estado a los cambios de la estructura por edades de la población son diferenciados". La Declaración naturalmente más que un catálogo de derechos es un acuerdo de capacitación, investigación, coordinación y asesoría regional en materia de vejez. CEPAL (2007). 
Puerto España, Trinidad y Tobago (2009) ${ }^{38}$; las resoluciones CD49.R15 (2009), Plan de Acción sobre la Salud de Personas Mayores incluido el Envejecimiento Activo y Saludable y CD50.R8 (2010) sobre la salud y los derechos humanos, aprobadas por su Consejo Ejecutivo de las $\mathrm{Na}$ ciones Unidas; la resolución AG/RES. 2654 (XLI-O/11), "Protección de los Derechos humanos de las Personas Mayores", aprobada en la cuarta sesión plenaria de la Asamblea General (2011); Segundo Foro Internacional sobre los Derechos Humanos de las Personas Mayores, Ciudad de México $(2014)^{39}$.

Sin perjuicio que las convenciones internacionales reconocen que lo esencial de la ancianidad es su protección; también, en los últimos años, se ha comenzado a reconocer el respeto a su autonomía. Los Principios de las Naciones Unidas, en favor de las personas de edad de 1991, establecen cinco campos en los cuales se reconoce su protección y derechos tales como:

- la independencia (numerales 1 a 6 ),

- participación (numerales 7 a 9),

- cuidados (numerales 10 a 14),

- autorrealización (numerales 15 y 16) y

- dignidad (numerales 17 y 18).

72 La preocupación por la mantención de altos grados de autonomía en esta materia se puede apreciar claramente en los referidos principios ${ }^{40}$.

${ }^{38}$ En dicha cumbre, las Jefas y Jefes de Estado y de Gobierno, se comprometieron a: "continuar trabajando para incorporar los temas de la vejez en las agendas de política pública y a promover, en el marco regional y con el apoyo de la OPS y de la CEPAL, un examen sobre la viabilidad de elaborar una convención interamericana sobre los derechos de las personas mayores".

${ }^{39}$ CEPAL (2014).

${ }^{40}$ En la regulación de la independencia y la dignidad de las personas mayores al acento se pone en los aspectos asistenciales que debe proveer fundamentalmente el Estado. En lo que respecta al cuidado, a pesar que los Principios de las Naciones Unidas en favor de las personas de edad se centran también en consideraciones asistenciales, se presenta un fuerte contenido de reconocimiento a la autonomía de las personas mayores en el numeral 14. Así, el referido numeral prescribe: "las personas de edad deberán poder disfrutar de sus derechos humanos y libertades fundamentales cuando residan en hogares o instituciones donde se les brinden cuidados o tratamiento, con pleno respeto de su dignidad, creencias, necesidades e intimidad, así como de su derecho a adoptar decisiones sobre su cuidado y sobre la calidad de su vida". Por otra parte, respecto de la autorrealización se combinan ambas posibilidades al establecer un criterio asistencial en el numeral 16 y de reconocimiento de su autonomía en el numeral 17, que dispone: "las personas de edad deberán tener acceso a los recursos educativos, culturales, espirituales y recreativos de la sociedad”. Por último, en cuanto a los derechos de participación se les reconoce a los ancianos un importante grado de autonomía. De este modo se señala: "7. Las personas de edad deberán permanecer integradas en la sociedad, participar activamente 
Esta tensión entre estas dos dimensiones de la ancianidad se ha puesto en evidencia durante el presente siglo ${ }^{41} \mathrm{y}$, como sucede respecto de la adolescencia, el reto es establecer un modelo regulatorio que sea capaz de, sin descuidar los aspectos asistenciales, prolongar la personalidad, la autonomía y la capacidad en las personas ancianas.

En nuestro país, la inclinación por una visión asistencial de la ancianidad casi no tiene contrapeso. De este modo, se aprecia en la regulación de la previsión social -que se aborda en DL No 3.500 (1980)- y de la relativa a la violencia en la familia -en la Ley sobre Violencia Intrafamiliar (leyes $\mathrm{N}^{\circ} 19.325$ de 1994 y 20.066 del 2005)-. Así sucede también en la regulación que hace la ley $\mathrm{N}^{\mathrm{o}} 19.828$, que dio lugar al SENAMA (2001). En nuestro Derecho, la protección en el ámbito constitucional de la ancianidad es solo indirecta, como se aprecia en los artículos 18 de la $\mathrm{CPE}$, que consagra el libre acceso de todos los habitantes al goce de prestaciones básicas uniformes, sea que se otorguen a través de instituciones públicas o privadas, y el adecuado ejercicio del derecho a la seguridad social; 16 de la CPE, que consagra la libre contratación y a la libre elección del trabajo con una justa retribución, etc. Tal vez, el campo que más ha reflejado la preocupación por la protección de la ancianidad ha sido el campo de la investigación científica y en cierto grado del consentimiento médico informado ${ }^{42}$.

Finalmente, este escenario ha comenzado a cambiar. De este modo, la Conferencia Regional Intergubernamental sobre Envejecimiento, celebrada en noviembre de 2003, en Santiago de Chile, culminó con la adopción de una estrategia regional de implementación para América Latina y el Caribe del Plan de Acción Internacional de Madrid, que en su objetivo 16, establece como objetivo: Promover los derechos humanos de las personas mayores, y para lo cual recomienda:

“(a) Incorporar explícitamente los derechos de las personas mayores a nivel de políticas, leyes y regulaciones. (b) Elaborar y proponer legislaciones específicas que definan y protejan estos derechos,

en la formulación y la aplicación de las políticas que afecten directamente a su bienestar y poder compartir sus conocimientos y pericias con las generaciones más jóvenes”.

${ }^{41}$ CEPAL (2011).

${ }^{42}$ Véanse artículos 28 de la ley $\mathrm{N}^{\circ} 20.584$ y 11 de la ley $\mathrm{N}^{\circ} 20.120$ y Convención de Naciones Unidas sobre Derechos de las Personas con Discapacidad. Pero en esta materia falta mucho camino por recorrer. Ello fundamentalmente se debe a que la visión proteccionista debe ser corregida, cuando sea necesario, por una visión en que prime la promoción del ejercicio autónomo de los derechos de la ancianidad. Además, el ámbito de protección debería extenderse a los casinos de juego y a la autonomía de la voluntad (testamento vital). 
de conformidad con los estándares internacionales y la normativa al respecto aceptada por los Estados. (c) Crear mecanismos de monitoreo a través de los organismos nacionales correspondientes".

A pesar de que el Estado chileno ha reconocido este cambio de paradigma -que incorpora a la protección de la ancianidad, el respeto y desarrollo de los derechos en esta materia-, como se verá, no hemos desarrollado las reformas legislativas tendientes al desarrollo de los derechos de la ancianidad.

\section{Los problemas que presenta la actual regulación de la capacidad de ejercicio respecto de la ancianidad en Chile}

A continuación se analizará si las reglas dadas en materia de capacidad, en lo relativo a la demencia, y las reglas generales del Derecho Común permiten un ejercicio adecuado de los derechos de la ancianidad.

a. La interdicción por demencia es una solución insuficiente a los problemas de capacidad respecto del adulto mayor

La incapacitación, en nuestro sistema jurídico, lleva al absurdo de que el juez o la ORC, en su caso, se enfrenten a la disyuntiva de dar lugar a una incapacidad absoluta -con todos los efectos que ello acarrea- o, simplemente, el deber de desechar la demanda de incapacidad. Esta no es una solución respetuosa de los derechos fundamentales del individuo, que sufra estos trastornos, por cuanto de tener solo una capacidad menguada -aun en el campo patrimonial-, como ocurre en la mayoría de los casos, el juez debería desechar la demanda. Esta tampoco es una solución eficiente, por cuanto el sujeto, al gatillarse su trastorno, no estará protegido por el Derecho y si se le incapacita, entonces no se le dejará actuar en la vida jurídica a pesar de que su enfermedad no se manifieste. Por ello, en el Derecho Comparado, lo que se hace es crear un verdadero traje a la medida, distinguiendo actos según sean patrimoniales -respecto de los que, a su vez, se puede distinguir en razón de su entidad económica- y actos no patrimoniales. A este propósito se puede decretar que un incapacitado es por regla general capaz, pero en relación con algunos actos personales, como el reconocimiento de hijos y el matrimonio requiere de autorización judicial, respecto de otros, requerirá complementar su voluntad con la de su cónyuge o uno de sus padres o un pariente cercano, y finalmente para disponer de inmuebles, y contraer deudas relevantes requiera de autorización del juez ${ }^{43}$. También el juez tiene la facultad de autorizar al incapacitado para

${ }^{43}$ Esto sucede en la incapacitación parcial cuantitativa que para Xavier O'Callaghan es la privación de la capacidad de obrar para ciertos actos jurídicos, no todos, por lo que 
la realización de ciertos actos, conforme a lo que aconsejen los respectivos informes psicológicos ${ }^{44}$. Una solución de esta clase se aplica en Chile solo a propósito de los declarados discapacitados mentales, siendo menores de edad (por oligofrenia, retardo o síndrome de Down). Ellos de acuerdo con el artículo $4.2^{\circ}$ (parte final) de la ley $\mathrm{N}^{\circ} 18.600$ pueden trabajar con la autorización de su curador ${ }^{45}$. Por otra parte, el art. $465 \mathrm{del} C C \mathrm{ch}^{46}$-que establece los efectos del decreto de incapacitación o interdicción- tiene una aplicación bastante restrictiva. Así, el decreto de interdicción para buena parte de nuestra doctrina solo produce sus efectos propios en torno a los actos jurídicos y contratos del demente, sean unilaterales o bilaterales, pero no en la responsabilidad extracontractual ${ }^{47}$. Por lo que no es del todo claro que esta norma se deba aplicar respecto de los actos extrapatrimoniales, realizados por un demente, o un anciano que sea declarado como tal por decreto de interdicción. Estimamos que la referencia que hace la norma sobre "los actos y contratos", excluye los actos extrapatrimoniales, como la sucede con la responsabilidad extracontractual. En todo caso, este punto es bastante discutido a propósito del matrimonio. Así, Manuel Somarriva señalaba que el art. 465 del $C C$ ch no tiene cabida respecto de dichos actos, por cuanto las referencia a "los actos y contratos" es a actos patrimoniales, en cambio, una parte importante de la doctrina sostenía lo contrario ${ }^{48}$.

conservará la capacidad para los demás actos; e incapacitación parcial cualitativa, si no le priva de la capacidad de obrar sino que la restringe en el sentido de que para todos o parte de los actos jurídicos se le impone el complemento de capacidad que le otorgará un curador. O'CALlaghan (2000), pp. 51-52.

${ }^{44}$ Gerardo Muñoz distingue situaciones de capacidad que denomina intermedias, como las siguientes: minoría de edad, pérdida de capacidad progresiva, discapacidad flexible física o psíquicamente permanente y capacidad interna e incapacidad de comunicación o expresión. MuÑoz (2000), pp. 61-62.

${ }^{45}$ Corral (2011), p. 46. En realidad a propósito de estos menores se produce algo parecido a la prórroga de la patria potestad del Derecho español. BARCIA (2003), pp. 391-424.

${ }^{46}$ La referida norma establece: "los actos y contratos del demente, posteriores al decreto de interdicción, serán nulos; aunque se alegue haberse ejecutado o celebrado en un intervalo lúcido.

Y por el contrario, los actos y contratos ejecutados o celebrados sin previa interdicción, serán válidos; a menos de probarse que el que los ejecutó o celebró estaba entonces demente".

${ }^{47}$ El decreto de interdicción, respecto de la responsabilidad extracontractual, es solo una prueba más. Alessandri (1983), pp. 134 y 135; Barros (2007), pp. 66-67; Corral (2004), pp. 107-108; TAPIA (2006), pp. 185-186.

${ }^{48}$ Manuel Somarriva agregaba que la doctrina civil, anterior a la LMC de 1884, excluía claramente la aplicación del art. 465 al matrimonio. Y, ello sucedía a pesar de que en el Proyecto de la referida ley se derogó una norma, que impedía la aplicación del art. 465 al matrimonio. En contra se manifiesta René Ramos Pazos que señala, siguiendo a Eugenio Velasco, que no había inconveniente para aplicar el art. 465 al matrimonio. Finalmente, Arturo Alessandri B. advierte que la NLMC zanjaría la discusión al no 
Sin perjuicio de lo anterior, el Derecho chileno no otorga las herramientas necesarias para que el juez pueda proceder a no inhabilitar totalmente a una persona, a través de la incapacidad absoluta, procediendo a una incapacitación de acuerdo con la inhabilidad concreta que afecta al incapaz. Por ello, instamos que se faculte, de lege ferenda, a los jueces, a través de la interdicción, a incapacitar a las personas de acuerdo con la inhabilidad que les afecte.

b. La aplicación de las reglas del Derecho Común como un paliativo a los problemas de regulación de la incapacidad es insuficiente

La inadecuación de las normas del Derecho Común, para permitir que los ancianos puedan regular su propia incapacidad cuando están lucidos, como podría ser el caso de un adulto mayor que se le diagnóstica Alzheimer de forma muy precoz, es evidente. De este modo, los contratos de mandato; renta vitalicia o cesión de bienes a cambio de alimentos o renta; sociedad, o la creación de personas sin fines de lucro son soluciones parciales a los problemas de la ancianidad. Así, una persona en su sano juicio podría otorgar un mandato para que una persona de confianza administre sus bienes ante una posible incapacidad, o mediante una sociedad unipersonal un futuro incapaz podría buscar que una persona cercana administre su patrimonio, aportando la mayoría de sus bienes a la sociedad. También es posible instituir en el testamento a un heredero que se vaya ocupando de los cuidados del adulto mayor (establecimiento de un delegado o fiduciario del testador o instituyendo herederos de confianza o legados a como compensación al cuidado de la persona mayor). Sin perjuicio que es posible recurrir a estas figuras, la mayoría de ellas están reguladas para promover el tráfico y no para proteger eventuales incapacidades. Así, tenemos que a propósito de la sociedad no se puede recurrir a esta solución, a lo menos respecto de las reglas de la sociedad colectiva civil, salvo que la incapacidad se regule expresamente en el estatuto social ${ }^{49}$. Por otra parte, aunque el mandato post-mortem está reconocido de manera expresa en nuestro Derecho en el artículo 2169 del $C C$ ch, no lo está el mandato para administrar el patrimonio del incapaz. Es más, dicha posibilidad, en principio, está prohibido por aplicación del artículo 2163, No 7 del $C C$ ch, que consagra que el poder de administración cesa por incapacitación del

referirse al demente, sino al que "se hallare[n]privado del uso de razón", por lo que se debe atender a la concurrencia del uso de razón, más que a la interdicción por demencia. Alessandri B. (2011), pp. 433-436.

${ }^{49}$ En este sentido, cabe recordar el artículo 2106 del $C C$ ch, que establece: "Expira asimismo la sociedad por la incapacidad sobreviniente o la insolvencia de uno de los socios.

Podrá, con todo, continuar la sociedad con el incapaz o el fallido, y en tal caso el curador o los acreedores ejercerán sus derechos en las operaciones sociales". 
mandante ${ }^{50}$. Por último, la institución de un legatario o heredero, como agradecimiento por los cuidados prestados al adulto mayor en su ancianidad, se topará con la regulación de las asignaciones forzosas.

c. Falta de una regulación específica de la ancianidad en el ámbito general

La Constitución sienta los cimientos de la institucionalidad y reconoce a la familia como la base sobre la que se constituye la sociedad. Sin perjuicio de lo cual, la concepción de la familia ha estado cambiando fuertemente los últimos cincuenta años ${ }^{51}$. Ello, por lo demás, como destaca Javier Barrientos, ha sido reconocido por un fallo de la Corte Suprema, de 31 de mayo de 2004, que diferencia el concepto legal de familia del concepto material $^{52}$. Pero a pesar de los vertiginosos cambios que ha sufrido la familia, es indudable que ella determina lo que somos en sociedad ${ }^{53}$. Por esto, no es de extrañar que el artículo $1.2^{\circ}$ de la CPE considera a la familia como "el núcleo fundamental de la sociedad". El mismo precepto se reitera en el artículo $1.1^{\circ}$ de la LMC, que, a su vez, agrega: "el matrimonio es la base principal de la familia" ${ }^{54}$. En igual sentido nuestra legislación reconoce cada vez con más fuerza el principio de la protección de los niños y adolescentes, a través del principio del interés superior del niño. Este es, sin lugar a duda, el principio fundamental a través del cual se articula el Derecho de la Infancia y Adolescencia. Así se desprende tanto de los artículos $2.1^{\circ} ; 4 ; 7.2^{\circ} ; 27.3^{\circ} ; 32$ y 41 de la $\mathrm{CDN}$, como de una serie de normas de Derecho interno (arts. $222.2^{\circ}, 234.2^{\circ}, 242.2^{\circ}$, primera parte, $225.3^{\circ}, 245.3^{\circ}$ del $C C \mathrm{ch}, 16$ de la LTF, $3.1^{\circ}, 27.2^{\circ}, 54.1^{\circ}, \mathrm{N}^{\circ} 5$ y 6 , ex $74.3^{\circ} \mathrm{y}$

${ }^{50}$ En el Derecho Comparado subsiste el poder en caso de incapacidad del poderdante, pero solo si se inscribe en un registro especial (sistema irlandés, griego, de Quebec) y en Alemania se permiten los poderes causalizados, esperando futura incapacidad (vorsogevollmacht), estas figuras están sujetas a revisión por los tribunales

${ }^{51}$ La familia nuclear, de acuerdo con la historia de Chile, ha sido una excepción, salvo entre la década de 1930 y 1970. Para Ximena Valdés, la tasa de hijos nacidos fuera del matrimonio en los años sesenta llega al piso histórico de 16\% de los hijos nacidos vivos. VAldÉs (2009), p. 389. En igual sentido véase Del Picó (2010), pp. 54-62.

${ }^{52}$ Barrientos (2011), p. 5.

${ }^{53}$ Como destaca Javier Barrientos: "la familia y la vida en ella constituye un espacio vital en el que las personas pueden perseguir y alcanzar 'su mayor realización espiritual y material posible' y, desde esa perspectiva, la citada base de la institucionalidad que se declara en el inciso $3^{\circ}$ del artículo $1^{\circ}$ de la Constitución Política de la República informa y explica el que la familia ocupe un lugar central en el derecho de las personas, en cuanto a que todas tienen un determinado status familiae". BARRIEnTOS (2011), p. 3.

${ }^{54}$ No es del caso referirse al matrimonio, pero es en esta institución en la cual la legislación busca que se desarrolle la familia, aunque todo indica que en los últimos años ello no acontece. 
$85.2^{\circ}$ de la LMC). Pero de todo este entrampado regulatorio, la ancianidad es el gran ausente, desde que en la familia los abuelos son los llamados a ocupar un papel absolutamente fundamental. No existe regla alguna, en la legislación civil, que se refiera de forma directa a la protección de los ancianos y su respeto como sujetos de Derecho. Nuestro Código solo se acuerda de los abuelos a raíz de los alimentos ${ }^{55}$ y recién el año pasado se ha reconocido de forma expresa el derecho de visitas, que asiste a los abuelos con relación a sus nieto ${ }^{56}$. Además, el Código Civil establece reglas en torno a los ascendientes como legitimarios en el Derecho Sucesorio.

La regulación de la tercera edad se articula conforme al concepto de persona mayor, que comprende a las personas que han cumplido setenta años ${ }^{57}$. Por ello, tal vez sería bueno actualizar el artículo 26 del $C C$ ch en torno los nuevos conceptos de niño, adolescente y persona mayor.

La crítica que se hace en este trabajo a la regulación de la capacidad en materia de ancianidad, no es solo que falta una regulación programática sino, principalmente, que las normas que regulan la incapacidad no son respetuosas de los derechos de esta.

d. La solución a la deficiencia regulatoria: un estatuto regulatorio civil programático respecto de la ancianidad,que contenga reglas que regulan la incapacidad en la ancianidad

En Chile, de lo señalado respecto del Derecho Comparado, se aprecia que no se reconoce a las personas de edad como individuos con capacidad de ejercicio limitada, sino que derechamente se obliga a los jueces a proceder a la incapacitación o adscribirlos al estatuto de capacidad general. Uno de los ordenamientos jurídicos más desarrollados, en torno a esta materia, como destaca Cristina de Amunátegui es el del Reino Unido. La Mental Capacity Act, publicada el 2005,permite que las personas otorguen poderes indefinidos (lasting powers of attorney) para la época en que se presente la incapacidad. Naturalmente, la ley articula un sistema de decisión judicial para el caso que la persona capaz no haya otorgado estos poderes de incapacitación. A dicho efecto las Cortes son apoyadas por un Public

${ }^{55}$ En este sentido, el artículo 232 del $C C$ ch dispone: "la obligación de alimentar y educar al hijo que carece de bienes, pasa, por la falta o insuficiencia de los padres, a sus abuelos, por una y otra línea, conjuntamente".

${ }^{56}$ La ley N²0.680 del 2013 agregó al Código Civil un nuevo artículo 229-2ª que es del siguiente tenor: "el hijo tiene derecho a mantener una relación directa y regular con sus abuelos. A falta de acuerdo, el juez fijará la modalidad de esta relación, atendido el interés del hijo, en conformidad a los criterios del artículo 229".

${ }^{57}$ Las personas mayores comprenderían la tercera y cuarta edad. Sin perjuicio de lo cual, conforme al artículo $1.2^{\circ}$ de la ley $\mathrm{N}^{\circ} 19.828$ : "para todos los efectos legales, llámase adulto mayor a toda persona que ha cumplido sesenta años". LATHrop (2009), pp. 81-84. 
Guardian y la ley se ocupa en especial de los aspectos no patrimoniales de la personalidad, que se ven afectados por la incapacitación ${ }^{58}$. Lo esencial de esta regulación, como de la mayoría de la que proviene del Derecho Comparado, es que se establece un rango gradual de protección para la ancianidad que hace frente no solo a la pérdida de facultades sino a la necesidad de protección de esta, sin que sea necesario incapacitarlo del todo. En cierto modo se separa la ancianidad de la incapacitación por pérdida de facultades. Y en los casos en que se deben tomar decisiones por el mayor adulto, con problemas cognoscitivos, se debe seguir su voluntad expresa (en la medida que haya dejado instrucciones cuando todavía era capaz) o tácita. Esta última se desprendería de los valores y actuaciones del incapaz cuando no estaba sometido a la incapacidad.

La gran falencia del sistema regulatorio chileno es que no hace frente a la ancianidad como un fenómeno específico. Así, en la actualidad, desde un prisma propio del Derecho Civil, los problemas de la ancianidad se abordan desde la incapacidad, VIF o los contratos; pero no existe una regulación que la reconozca que debe ser regulada desde un prisma específico.

La falta de una regulación civil, respecto de ella, se puede apreciar desde las siguientes perspectivas:

i. La persona mayor de edad se protege en los Derechos decimonónicos, como el nuestro, a través de las incapacidades. Dichas reglas son muy inadecuadas, desde dos perspectivas. En consideración a la primera, la pérdida de la capacidad por parte de los adultos mayores se regula a través de la incapacidad absoluta, en específico a través de la demencia. Ello es una mala técnica para incapacitar por cuanto obliga a los jueces a dar lugar, a través del decreto de interdicción, a una incapacidad absoluta o simplemente a dejar a personas, que requieren grados menores de protección, desprotegidas. Esto último no solo sucede con personas ancianas, que presentan pérdida de su capacidad volitiva sino, también, respecto de personas que tengan enfermedades psicológicas, como la bipolaridad ${ }^{59}$.

${ }^{58}$ De Amunátegui (2008), pp. 29-31.

${ }^{59} \mathrm{El}$ procedimiento a través del cual se inhabilita totalmente a los ancianos tampoco parece ser el más adecuado. En este sentido el proceso de incapacitación debe ser abordado desde una perspectiva procesal-garantista, exigiéndose un procedimiento inquisitivo y contradictorio propio de la ancianidad con pruebas preceptivas como audiencia de los parientes más próximos, examen del tribunal, informe médico, obligación de declarar del incapacitado exigencias de internamiento, etc. Además, debería haber procesos de revisión de la incapacidad en sentido horizontal (ampliar o restringir la incapacidad) o en sentido vertical (cambio de tutela y curatela y viceversa). En el Derecho Comparado la tendencia es a regular a la ancianidad a través de la prodigalidad y no a través de la demencia. 
La segunda perspectiva, conforme a la cual las reglas de incapacidad son inadecuadas para proteger la ancianidad, radica en la falta de reconocimiento de la autodeterminación de las personas ancianas para decidir cómo regular su pérdida de capacidad.

En este sentido hace falta la adopción del principio general de proteger sin incapacitar, como sucede en Alemania, España o en Francia. Por ello, incluso, es recomendable incluir el término de cuasicapacidad o graduación en la capacidad/incapacidad. Así, la sentencia de incapacitación debe obedecer a un proceso de gradualidad en la incapacidad, que distinga entre aspectos personales (reconocimiento de hijos, matrimonio, testamento, etc.) y patrimoniales: contratación directa, autorización tanto de la cónyuge o pariente como del juez, ascenso, complementación de la voluntad y representación ${ }^{60}$.

ii. El principio fundamental en esta materia es el de la autorregulación del propio interesado. En atención a este principio es posible ordenar toda la legislación relativa a la ancianidad. Ello se logra a través de la autotutela o autodelación (Derecho catalán), documento formal y revocable (positivo o negativo de autotutela), nombramiento de un tercero como curador (bertreuer en el Derecho alemán ${ }^{61} \mathrm{O}$ al mandat de protection future del Derecho francés $)^{62}$.

${ }^{60}$ En España desde la ley No 13 de 1983 la incapacitación no reconoce categoría cerradas y existe un concepto general como la falta de la aptitud para autogobernarse.

${ }^{61}$ El Derecho alemán se ocupa de la ancianidad en varias normas. Así, en los $\S \S$ 1901.a a 1904 del $B G B$ regula el testamento vital. En el Derecho alemán se permite que la incapacidad sea regulada por el propio incapaz, a través del nombramiento de curador y por las instrucciones que le deja el incapaz; pero obviamente estas facultades, en cualquier momento, pueden revocarse. El curador, de no existir testamento vital, debe hacer todo lo posible por investigar cual hubiese sido la voluntad del paciente (cómo si se debe permitir o no un tratamiento médico), para ello debe considerar aspectos reales, no simples apreciaciones, como testigo que señalen la opinión del paciente en aspectos éticos, religiosos, etc. En realidad el curador debe determinarse la filosofía de vida del paciente. Por otra parte, nadie puede ser obligado a dejar un testamento vital, ni a dejar la firma de un contrato sujeto a su firma (\$ 1901.a del $B G B)$.

El curador, de acuerdo con el $\S 1901 . b$ del $B G B$, debe lograr un convencimiento para reconstruir la voluntad del paciente. El médico tratante y el curador debe fijar un tratamiento de acuerdo a su estado general y diagnóstico del paciente, que considere su voluntad, para su determinación se deberá escuchar a personas de confianza del enfermo y parientes, sin afectar su salud.

${ }^{62}$ El art. 477 del Code, modificado por la ley No 2007-308 de 5 de marzo de 2007, estableció el denominado mandato de protección futura (mandat de protection future). De acuerdo con este mandato cualquier adulto o menor emancipado, que no sean objeto de tutela, podrá nombrar como mandatario una o más personas para el efecto de ser representada en los supuestos del artículo 425. Dicho contrato se puede celebrar por 
iii. Falta de incorporación de una serie de figuras reconocidas en el Derecho Comparado, como el patrimonio protegido de las personas con discapacidad. En el Derecho español se ha incorporado esta figura fundamental en la protección de la ancianidad y respeto de la autodeterminación de los ancianos (ley $\mathrm{N}^{\circ} 41 / 2003$, que fue modificada por la ley $\left.\mathrm{N}^{\circ} 1 / 2009\right)^{63}$. El papel de la regulación de este patrimonio es doble, por cuanto busca mantener una autonomía en el discapacitado, y protegerlo cuando ella no se pueda ejercer de forma directa por este, pero respetando su voluntad. En consideración a estas reglas se regula una masa patrimonial, que queda sujeta a reglas que el propio discapacitado establece, y es destinado a la satisfacción de las necesidades vitales del beneficiario (art. $5.4^{\circ}$ de la ley $\mathrm{N}^{\circ} 41 / 2003$ ). A ellas subsidiariamente se les aplica el estatuto legal de los guardadores. Esta figura tiene su antecedente en los países del Common Law, en los Trust fund. Lo interesante de estos fondos es que buscan profesionalizar la administración de fondos para la vejez o enfermedad, mezclando políticas públicas con autonomía o capacidad limitada.

escritura pública o privada. En conformidad al art. 425 del Code, toda persona que esté en la imposibilidad de ocuparse por sí sola de sus propios intereses en razón de una alteración, comprobada por un médico, de sus facultades mentales, sea de sus facultades corporales o que esté impedida de expresar su voluntad puede beneficiarse de una medida de protección jurídica prevista en el presente libro (se refiere a la sección $1^{\mathrm{a}}$ del libro I: De las personas capítulo II, del Code). Si no se disponga otra cosa, la medida estará destinada tanto a la protección de la persona, como a los intereses patrimoniales de ésta. Por otra parte, este mandato de protección futura, conforme al art. 436 del Code, puede verse afectado por una medida de protección del pupilo de mayor entidad, decretada por el juez. La afectación del mandato no es automática y el juez podría dejar subsistente el mandato, pero reasignando las funciones del mandatario conforme a la nueva realidad. Véase www.legifrance.gouv.fr/affichCode.do;jsessionid=BD7886A6B61D5509243496FB 76C554EC.tpdjo09v_1?idSectionTA=LEGISCTA000006150531\&cidTexte=LEGITEXT 000006070721\&dateTexte=20140930. [Fecha de consulta: 19 de mayo de 2014]

${ }^{63}$ La constitución de este patrimonio la realiza el propio incapacitado en la medida que tenga la capacidad suficiente, o sus padres, tutores o curadores de acuerdo con los mecanismos generales de sustitución de la capacidad del obrar (art. 3 de la ley). Naturalmente, el patrimonio debe constar con un aporte originario, pero luego se pueden hacer aportaciones. En caso de aportaciones de terceros -que no sean los padres, tutores y curadores- siempre deberán hacerse a título gratuito (art. $4.2^{\circ}$ de la ley). La voluntad de la persona con discapacidad, que tenga capacidad de obrar suficiente podrá negarse al aporte de un tercero. No es del caso detallar toda la ley, pero ella contiene reglas de nombramiento de administrador (art. 3 de la ley), remisión y facultades, respecto de las cuales lo esencial es la voluntad de discapacitado, y, a falta de ella, se recurre a la solución legal (art. 5 de la ley). También la ley establece reglas de supervisión en la administración del patrimonio (art. 7 de la ley). 


\section{CONClusiones}

El presente trabajo ha evidenciado cómo, a pesar de que ha habido una preocupación por el adulto mayor desde la esfera de las políticas públicas, el Derecho Privado chileno no se ha actualizado en aspectos muy relevantes para la protección y desarrollo de sus derechos. Su falta de actualización se refleja en el área de la capacidad -como se aprecia de las reglas de interdicción- y la falta de incorporación de la ancianidad, a través de una regulación específica, que comprendería naturalmente la discapacidad. También se ha visto la impotencia del Derecho Común, sobre todo en torno a la regulación de los contratos, para permitir formas de autorregulación de la incapacidad por el propio incapaz, a través de los contratos de mandato o sociedad.

En definitiva, de lo analizado en esta investigación, se puede apreciar que el Derecho Civil chileno no está preparado para hacer frente a los problemas de la ancianidad y requiere de una reforma urgente, sobre todo respecto de la forma de ejercicio de los derechos por parte del adulto mayor.

\section{BiBLIOGRAFÍA CITADA}

Alessandri Besa, Arturo (2011). La nulidad y la rescisión en el Derecho civil chileno. $3^{\mathrm{a}}$ ed. actualizada. Santiago: Editorial Jurídica de Chile, tomo I.

Alessandri Rodríguez, Arturo (1983). De La Responsabilidad Extracontractual en el Derecho Chileno. $2^{\text {a }}$ ed. Santiago: Ediar Editores, tomo II.

Amunátegui Rodríguez, Cristina de (2006). “¿Crisis de la incapacitación? La autonomía de la voluntad como posible alternativa para la protección de los mayores". Revista de Derecho Privado, No 1-2. Madrid. Enero-febrero.

Amunátegui Rodríguez, Cristina de (2008). Incapacitación y mandato. Madrid: Editorial La ley.

Barcia Lehmann, Rodrigo (2000). "Análisis crítico de las reformas al Derecho de Familia Chileno". Gaceta Jurídica, No 242. Santiago.

Barcia Lehmann, Rodrigo (2002). "El convenio regulador en el Derecho español y el proyecto de Ley de Matrimonio Civil chileno". Revista Ius et Praxis, año $8, \mathrm{~N}^{\mathrm{O}} 2$, Talca.

Barcia Lehmann, Rodrigo (2003). "Análisis de la prórroga y rehabilitación de la patria potestad". Revista de la Facultad de Derecho, No 98. Madrid.

Barcia Lehmann, Rodrigo (2006). "Informe en Derecho sobre la capacidad de los menores para recibir la denominada píldora del día después". Revista de Chilena de Derecho Privado, No 7, Santiago. Diciembre.

Barcia Lehmann, Rodrigo (2011). "Principios en los que se inspiran el Derecho de Familia -en especial del matrimonio y de la infancia”, en Luis GuzMán 
(coord.). Nos Ad Justitiam Esse Natos, Libro de Homenaje a la Escuela de Derecho de la Universidad de Valparaíso en el Centenario de su fundación (1911-2011). Valparaíso: Ediciones Universidad de Valparaíso.

Barcia Lehmann, Rodrigo (2013a). "Facultades y derechos compartidos respecto de los hijos: Una mirada desde el derecho comparado". Revista de Derecho. Año 20 - $\mathrm{N}^{\mathrm{O}} 1$. Concepción.

Barcia Lehmann, Rodrigo (2013b). "La capacidad extrapatrimonial de los niños y adolescentes conforme a sus condiciones de madurez". Ius et Praxis, vol. $19, \mathrm{~N}^{0}$ 2. Talca.

Barcia Lehmann, Rodrigo y Carolina RiverosFerrada (2011). "El carácter extrapatrimonial de la compensación económica". Revista Chilena de Derecho, vol. 38 - No 2. Santiago.

Barranco, María del Carmen, Patricia Cuenca y Miguel Ángel Ramiro (2012). "Capacidad jurídica y discapacidad: el artículo 12 de la convención de derechos de las personas con discapacidad". Anuario Facultad de Derecho. Nv, Alcalá.

Barrientos Grandón, Javier (2011). Derechos de las personas. Santiago: AbeledoPerrot, LegalPublishing Chile, Thomson Reuters.

BARros Bourie, Enrique (2007). Tratado de responsabilidad extracontractual. Santiago: Editorial Jurídica de Chile.

CEPAL (2007).Declaración de Brasilia. Disponible en www.senama.cl/filesapp/2267. pdf. [Fecha de consulta: 25 de mayo de 2014].

CEPAL (2011).Los derechos de las personas mayores. Disponible en www.eclac.cl/ celade/noticias/documentosdetrabajo/2/43682/Modulo_1.pdf. [Fecha de consulta: 25 de mayo de 2014].

CEPAL (2014). Conclusiones. Segundo foro internacional sobre los derechos humanos de las personas mayores. Disponible en www.eclac.cl/celade/noticias/paginas/7/53017/Conclusioeswb2.pdf. [Fecha de consulta: 25 de mayo de 2014].

Corral Talciani, Hernán (2004). Lecciones de responsabilidad civil extracontractual. Santiago: Editorial Jurídica de Chile.

Corral Talciani, Hernán (2011). "Interdicción de personas que sufren trastorno de dependencia de la cocaína". Revista de Derecho de la Universidad Austral de Chile. Vol. XXIV, $\mathrm{N}^{\circ}$ 2, Valdivia.

De Castro y Bravo, Federico (1952). Derecho Civil de España. Madrid: Instituto de Estudios Políticos, tomo II: Derecho de la Persona. Parte primera. La persona y su estado civil.

Del Picó Rubio, Jorge (2010). Derecho matrimonial chileno. Santiago: Abeledo Perrot y Legal Publishing.

DíEz-Picazo, Luis (1989). "La figura del convenio regulador en el marco del negocio jurídico familiar y de los principios constitucionales del Derecho de Familia”, capítulo I, en Convenios Reguladores de las Crisis Matrimoniales. Pamplona: Instituto de Ciencias para la Familia, Ediciones Universidad de Navarra, SA. 
Díez-Picazo, Luis y Antonio Gullón (1998). Sistema de Derecho Civil. $9^{a}$ ed. Madrid: Editorial Tecnos.

Figueroa Yáñez, Gonzalo (2011). Derecho Civil de la Persona. Del Genoma al Nacimiento. Santiago: Editorial Jurídica de Chile.

Heredia Puente, Mercedes y Cristóbal Fábrega Ruiz (1998). Protección legal de incapaces. Madrid: Editorial Colex.

Kemelmajer, Aída (2006) "Las personas ancianas en la jurisprudencia argentina ¿hacia un derecho de la ancianidad?". Revista Chilena de Derecho, vol. 33. ${ }^{\circ}$ 1 , Santiago.

Larroumet, Christián (2006). Derecho Civil. Introducción a Estudio del Derecho Priva$d o$. Primera edición en español. (trad.)Viviana Díaz Perilla. Colombia: Legis.

Marín López, Juan (1996). Derecho Civil. Introducción. Derecho de la persona. Derecho subjetivo. Derecho de Propiedad. Madrid: Tecnos.

Meza Barros, Ramón (1995). Manual de Derecho de Familia. Santiago: Editorial Jurídica de Chile, tomo II.

MuÑoz DE Dios, Gerardo (2000). "El patrimonio del discapacitado", en La protección jurídica de discapacitados, incapaces y personas en situaciones especiales. Seminario organizado bajo la presidencia de honor de SM la reina de España por el Consejo General del Notariado en la UIMP, Rafael Martínez Díe (director del seminario). Madrid: Civitas Ediciones SL.

Naciones Unidas (2003). Declaración política y plan de acción internacional de Madrid sobre el envejecimiento. Disponible en http://undesadspd.org/Portals/0/ageing/ documents/Fulltext-SP.pdf. [Fecha de consulta: 14 de mayo de 2014].

O'Callaghan, Xavier (2000). "La declaración de incapacidad",en La protección jurídica de discapacitados, incapaces y personas en situaciones especiales. Seminario organizado bajo la presidencia de honor de SM la reina de España por el Consejo General del Notariado en la UIMP, Rafael Martínez Díe (director del seminario). Madrid: Civitas Ediciones SL.

Ramos Chaparro, Enrique (1995). La Persona y su capacidad civil. Madrid: Tecnos.

Somarriva Undurraga, Manuel (1983). Derecho de Familia. Santiago: Ediar Editores, tomo II.

TAPIa SuÁrez, Orlando (2006). De la responsabilidad civil en general y de la responsabilidad delictual entre los contratantes. Santiago: Lexis Nexis.

VALDÉs, Ximena (2009). "El lugar que habita el padre en Chile contemporáneo. Estudio de las representaciones sobre la paternidad en distintos grupos sociales". Polis. Vol. 8, $\mathrm{N}^{\circ}$ 23. Santiago.

VARAS, Juan Andrés (2009)."Decisiones vitales y representación parental: fundamento y límites", en Departamento de Derecho Privado. Universidad de Concepción (coord.). Estudios Derecho Civil V. Jornadas Nacionales de Derecho Civil, Concepción. Santiago: AbeledoPerrot, LegalPublishing.

Zurita Martín, Isabel (2004). Protección civil de la ancianidad, Madrid: Dykinson. Capítulo 3: La incapacitación del anciano. 


\section{Normativa citada}

Chile

Decreto 201, promulga la Convención de Naciones Unidas sobre Derechos de las Personas con Discapacidad. Y su protocolo facultativo, Diario Oficial, 17 de septiembre de 2008.

Decreto supremo N ${ }^{\circ}$ 49/2011, Ministerio de Planificación.

DFL 1/2000. Ministerio de Justicia, Fija texto coordinado refundido y sistematizado del Código Civil, de la ley N ${ }^{\circ} 4.808$, sobre Registro Civil, de la ley No 17.344 , que autoriza el cambio de nombres y apellidos, de la ley $\mathrm{N}^{\circ} 16.618$ ley de menores, de la ley $\mathrm{N}^{\circ} 14.908$, sobre abandono de familia y pago de pensiones alimenticias, y de la ley $\mathrm{N}^{\circ} 16.271$, de impuesto a la herencia, asignaciones y donaciones. Diario Oficial 30 de mayo de 2000.

Dictamen No 1449, de 14 de enero de 2003, Contraloría General de la República.

Ley No 18.600, establece normas sobre deficientes metales, Diario Oficial, 17 de febrero de 1987.

Ley $\mathrm{N}^{\circ}$ 19.828, crea el Servicio Nacional del Adulto Mayor, Diario Oficial, 27 de septiembre de 2002.

Ley 19.904/2003, Modifica los artículos 1.447 del Código Civily $4^{\circ}$ de la Ley de Matrimonio Civil, respecto de las causales de incapacidad que afectan a los sordomudos que no pueden darse a entender por escrito y a aquellos que de palabra o escrito no pudieren expresar su voluntad claramente, Diario Oficial, 3 de octubre de 2003.

Ley No 19.947, establece nueva Ley de Matrimonio Civil, Diario Oficial, 17 de mayo de 2004.

Ley $\mathrm{N}^{\circ} 20.120$ sobre la investigación científica en el ser humano, u genoma y prohíbe su clonación, Diario Oficial, 22 de septiembre de 2006.

Ley $\mathrm{N}^{\circ} 20.680$, introduce modificaciones al Código Civily a otros cuerpos legales con el objeto de proteger la integridad del menor en caso que los padres vivan separados, Diario Oficial, 21 de junio de 2013.

Ley $\mathrm{N}^{\circ} 20.584$, regula los derechos y deberes que tienen las personas en relación con acciones vinculadas a su atención en salud, Diario Oficial, 24 de abril de 2012.

Alemania

$B G B$

España

Ley $\mathrm{N}^{\circ} 1 / 2000$, de 7 de enero, de Enjuiciamiento Civil.

Ley $\mathrm{N}^{\circ} 13 / 1983$

Ley N²0/2011, del Registro Civil. 
Ley $N^{\circ}$ 41/2003, de 18 de noviembre, sobre Protección Patrimonial de las Personas.

Ley, $\mathrm{N}^{\circ} 1.856 / 2009$, de 4 de diciembre, de Dependencia.

Italia

Ley N ${ }^{\circ} 6$ del 2004.

\section{Jurisprudencia citada}

BVerfGE 7, 198 [Lüth]. 